\title{
Review
}

\section{The political is political: Conformity and the illusion of dissent in contemporary political philosophy}

\author{
Lorna Finlayson \\ Rowman \& Littlefield International, London, 2015, x+240pp., \\ ISBN: 978-1783482870
}

Contemporary Political Theory (2016) 15, e50-e53. doi:10.1057/cpt.2015.51; published online 6 October 2015

History shows there is no desirable alternative to liberalism. Dissenters from the status quo need to be constructive. Unless they can specify what they would put in place of existing social arrangements, they cannot expect to be taken seriously. In any case, liberalism can accommodate even its critics. While we can argue about the extent to which any set of political institutions can be genuinely neutral between different moral perspectives, we can agree that liberal ones have legitimacy precisely because they do not impose (or not too much) any particular vision of 'the good life' on individuals. Rather, the liberal state provides a framework within which free and equal citizens can disagree - so long as they are reasonable about it. In the real world, of course, liberal democracies have often, perhaps always, fallen short of liberal ideals, by excluding (either formally or de facto) certain groups from political participation, allowing economic power to undermine democratic processes, or engaging in drone warfare against civilians, for example. Yet that does not undermine the ideals themselves. To implicate liberal political philosophers in these real-world failures is uncharitable.

Such adages define the accepted parameters of debate within contemporary political philosophy. Yet, according to Finlayson, they deserve closer examination. Why, for instance, is Marx so easily dismissed as 'refuted by history', while pointing to the more bloody moments of Actually Existing Liberalism does not count as an argument against J. S. Mill? In this incendiary new study, Finlayson focuses critical attention on the methodological assumptions that suffuse the air of philosophy departments: that criticism of the dominant (liberal) view must always be 'constructive' and 'charitable', and that (love him or hate him) all must pay tribute to the great contribution of John Rawls. In each case, she argues, 'What is presented 
as politically neutral "common sense" turns out to be politically controversial, and the illusion to the contrary serves to reinforce the philosophical and political status quo' (p. 55). However, Finlayson does not argue against these methodological principles. She does not claim that there is no value to interpreting another's position charitably, or that it is illegitimate to ask a critic to suggest a feasible alternative to the thing they are criticizing. Rather, she shows how the ways in which these so far schematic demands are actually deployed involves a surreptitious 'filling in' with content which is itself political and in fact biased towards the more (small 'c') conservative position.

For instance, we can agree that it is a good thing for a proposal to be 'realistic' (which is not to say that an unrealistic proposal might not have other qualities, like being mind-opening, or beautiful). To be realistic means to take appropriate account of reality. However, in order for the instruction 'Be realistic!' to offer any guidance, it needs to be filled in with some views about what reality is like, including its causal relationships and possibilities for change. These, of course, are precisely the things that people with different political views are going to disagree on. So far, so obvious. As Finlayson shows, however, when the value of realism is invoked in political philosophy it tends to be assumed that taking appropriate account of the way that the world is involves accepting that it continues to be that way. As the debate is currently set up, in other words, all sides assume that realism equals conservatism compromising high-flown ideals in the face of hard facts.

Thus, while realist currents in political philosophy in one sense challenge the orthodoxy of so-called 'ideal theory' (which invents elaborate liberal utopias oblivious to the social power conditioning that very project), the conflation of takingaccount-of-reality with not-changing-reality actually locks discussion still further within a narrow liberal framework. On reflection, though, this equivalence is not something we have to accept. It is not always realistic to propose that something remain the same. Just because I am doing a headstand now does not mean you can make me continue to do a headstand indefinitely. Perhaps that is just not a sustainable arrangement. Push it too far and I will either collapse or rebel - or so a radical critic of this inverted reality might argue.

In Finlayson's analysis, then, familiar moves that are supposed to justify keeping political philosophy within the confines of liberalism are revealed as 'begging the question' against more radical positions. They rely on standards of assessment - such as the measure of a proposal as realistic to the extent that it demands only modest changes from existing institutions - which we would have reason to accept only if we already agreed with the dominant position. Rawls's doomed attempt to come up with a non-circular definition of 'reasonableness' such that all reasonable persons must accept his favoured political arrangements is a case in point. Having laid out exactly why this cannot work, Finlayson comments that Rawls might as well have talked about his system being justifiable to jolly decent chaps (p. 55). The image of political philosophers that emerges from these pages is hardly flattering: a comfortable 
orthodoxy propped up by double-standards which just so happen to serve those already in power, both inside and outside philosophy.

The discipline's own understanding of its role in 'real politics' also comes in for scrutiny. Finlayson shows how political philosophers' apparently innocuous statements about the worth of their own contributions in fact presuppose substantial (political) commitments about the nature of society and how social change can (or should) occur: "Just as the neoliberal idea is that wealth will "trickle down" from the top of a society to the bottom, the thought here seems to be that political philosophers' wisdom will percolate through the minds of politicians, through existing political structures, through the public culture and, in diluted form, through the muddled and distractible minds of the masses, who will then send such wisdom as they have absorbed back up into the political machine in the form of a stream of ballot papers' (p. 143).

The bias Finlayson identifies towards a conception of politics as policy (which 'limit[s] attention to the output of a given political system leaving aside more fundamental political questions of how that system is structured, who gets to decide what the "output" of the system should be, and how this is decided' (p. 144)) is particularly pronounced in another area which should disrupt the mainstream, yet is in serious danger of being co-opted by it: feminism. Finlayson argues that the (liberal) form of feminism which is currently gaining some ground within a still outrageously hostile discipline is limited by (i) its determination to squeeze every insight into the language of 'some big man's prior thought' (Catharine MacKinnon, cited p. 89), conceding this as a prerequisite for being taken seriously, and (ii) the background assumption that the only real political import which arguments about silencing, speech, pornography and freedom might aspire to is to lubricate sterile wranglings about what the liberal state should or should not censor.

Here Finlayson could perhaps have gone further in considering contradictions between the feminist project of challenging gendered violence and the legislative framework it tends to assume. She could have engaged with existing objections to what Victoria Law calls 'carceral feminism', which 'sees increased policing, prosecution and imprisonment as the primary solutions to violence against women', ignoring 'the ways in which race, class, gender identity, and immigration status leave certain women more vulnerable to violence and that greater criminalization often places these same women at risk of state violence' (Law, 2014). From this perspective, Catharine MacKinnon's own entanglements with law, which Finlayson brushes off as irrelevant to the particular argument she wants to make, might appear of more significance.

Finlayson's book will doubtless be found extremely irritating by the political philosophical establishment. What will be found most irritating is its skill in tracing the argumentative moves with which they will try to dismiss it. Precisely for this reason, though, people outside the narrow academic culture which is its direct object of criticism might assume her project to be of limited interest. This would be a 
mistake. Although her focus is on the somewhat rarified literature produced and consumed by the denizens of philosophy departments, the argumentative tricks and double-standards which she exposes all have their counterparts in everyday political discourse and no philosophical training is required to follow her lucid and often pithy writing style. Readers versed in more radical theory may find it frustrating how little Finlayson avails herself of existing critiques of liberalism, yet her dexterity in unmasking the internal contradictions of a discipline which, as she shows, is so loath to acknowledge even the existence of 'deep dissent' much less its validity, is also what is distinctive about this book. Equally, that this dexterity evidently comes in part from her own background in that discipline is a good lesson in not throwing out babies with bathwater. It would obviously be an overstatement to say that analytic political philosophy has produced its own grave-digger. Perhaps, though, it will reveal something of itself in how it chooses to deal with this enemy within.

\section{Reference}

Law, V. (2014) Against carceral feminism. Jacobin [Online], https://www.jacobinmag.com/2014/10/ against-carceral-feminism/, accessed 30 August 2015.

Koshka Duff

University of Sussex, Brighton, BN1 9RH, UK 